\title{
Towards Green Economics and Society: Exploring the Efficiency of New Energy Generation
}

\author{
Guoqing Ye, ${ }^{1}$ Xin Long Xu, ${ }^{2}$ Yujie Chen, ${ }^{3}$ and Kai Quan Zhang $\mathbb{D}^{4,5}$ \\ ${ }^{1}$ State Grid Zhejiang Dongyang Power Supply Co., Ltd., Dongyang 322100, China \\ ${ }^{2}$ College of Tourism, Hunan Normal University, Changsha 410081, China \\ ${ }^{3}$ Faculty of Hospitality and Tourism Management, Macau University of Science and Technology, Taipa 999078, Macau \\ ${ }^{4}$ School of Economics, Xiamen University, Xiamen 361005, China \\ ${ }^{5}$ School of Economics and Business Administration, Longyan University, Longyan 364012, China \\ Correspondence should be addressed to Kai Quan Zhang; zhangkaiquan_ly@sina.com
}

Received 30 July 2021; Revised 21 October 2021; Accepted 15 November 2021; Published 3 December 2021

Academic Editor: Qiuye Sun

Copyright ( $\odot 2021$ Guoqing Ye et al. This is an open access article distributed under the Creative Commons Attribution License, which permits unrestricted use, distribution, and reproduction in any medium, provided the original work is properly cited.

\begin{abstract}
In recent years, solar and wind energy have been increasingly abandoned due to the blind expansion of the new energy industry. Due to the competitive relationships between different types of new energy, reasonable industrial development planning needs to be implemented to not only save the cost of government subsidies but also clarify the investment direction of social capital. Based on the panel data of OECD countries between 2006 and 2018, the stochastic frontier analysis (SFA) was used to measure the efficiency of new energy generation (NEG) and the influencing factors were analyzed in this paper. Results were as follows: the efficiency of NEG in OECD countries is improving; the efficiency of NEG is positively correlated with technical innovation, government policies, economic level, and education level and negatively correlated with urbanization. Based on the empirical results of this study, problems in the development of the new energy industry have been discussed and suggestions to improve the efficiency of NEG have been proposed.
\end{abstract}

\section{Introduction}

With the fast development of new energy and the increasing maturity of technologies in recent decades, new energy products have been accepted and occupy the corresponding market in the economy [1-3]. The percentage of new energy to traditional energy has increased to $9.6 \%$ in 2017 , and the percentage of wind and solar energy in primary energy consumption has increased rapidly [4]. As shown in Figure 1, although the proportion of global new energy consumption in primary energy consumption is currently still low, developed countries, including the USA, Japan, and South Korea, are developing new energy as their main future energy source [5]. Meanwhile, many countries have also formulated their new energy development plans [6]. Both the "Sino-US Joint Statement on Climate Change" and the "Energy Strategic Action Plan (2014-2020)" state that nonfossil energy will be close to approximately $20 \%$ of primary energy consumption by 2030 in China [7]. China accounted for $34 \%$ of the world's wind energy installed capacity and $19 \%$ of the world's solar energy installed capacity in 2015, ranking first in the world [8]. There are some overlaps in the conceptual classification between new energy and renewable energy. Besides, hydropower is usually classified as renewable energy rather than new energy. Therefore, this paper defines the new energy as renewable energy except for hydropower according to the energy status of development and utilization in China.

However, the rapid development of new energy not only provides a unique opportunity for new energy enterprises but also can create a bubble effect that impacts all of society. Given a background of rapid mergers and reorganization, conventional energy enterprises are eager to transition to new energy industries but fail to combine this transition with their own operating experience [9]. Other business entities, such as venture capital and private capital, are also eager to 


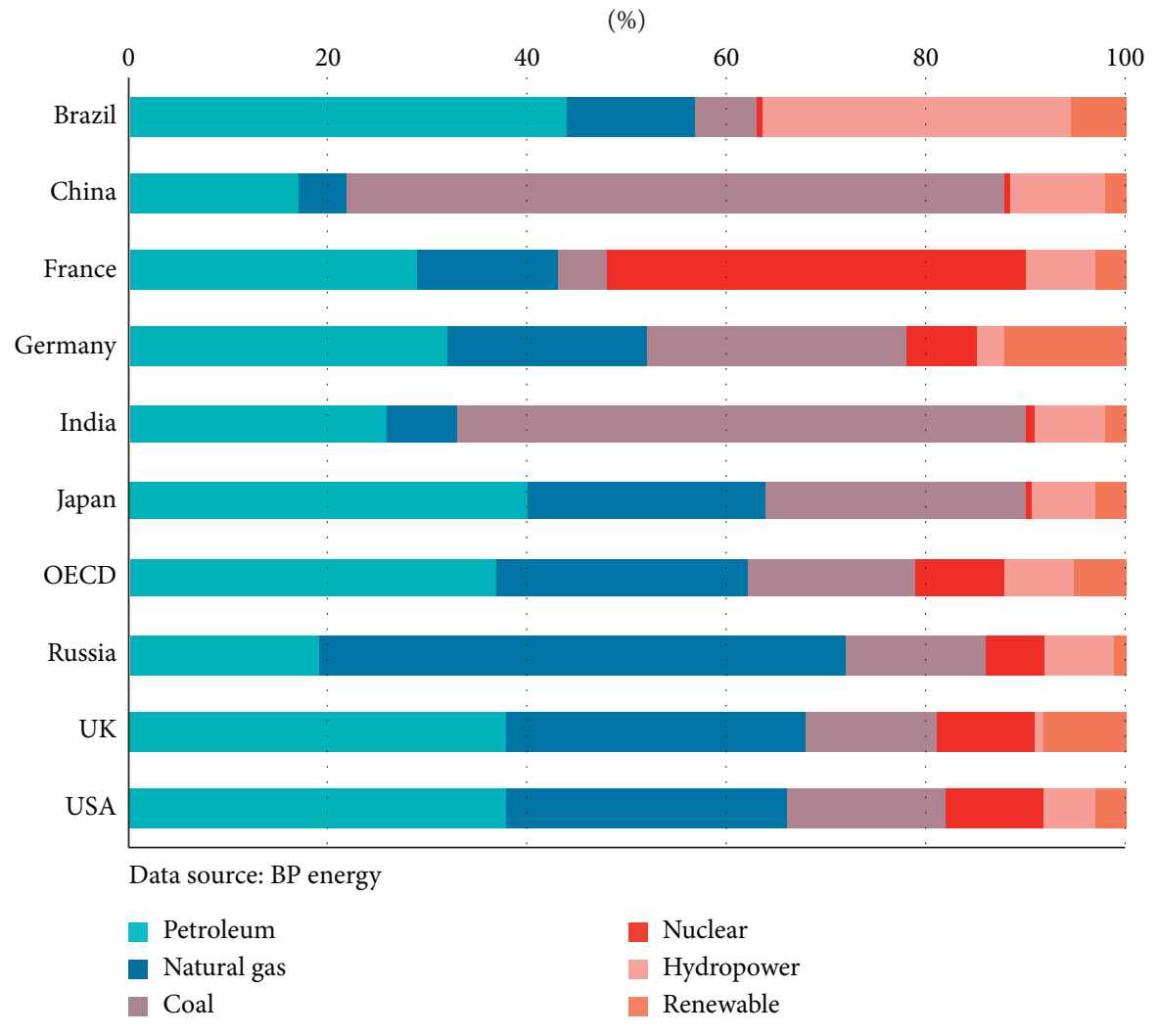

FIGURE 1: The energy consumption patterns of major countries and economies in 2018.

invest in new energy sectors [10-12]. The phenomenon of low-level mergers and blind investment has created serious overcapacity and reduced production efficiency in new energy industries. Meanwhile, several disadvantages will affect the sustainable development of the new energy industry: the speed of new energy development in China has soared, core technologies lack independent intellectual property rights, investment in R\&D is decreasing, new energy products are tending towards homogeneity, and the cost of new energy generation (NEG) is high [13]. Furthermore, the sustainable development of new energy will affect China's ability to realize its carbon emission commitment and the future sustainability of its green economy [14-16]. As a strategic emerging industry, the development of the new energy industry plays an irreplaceable part in upgrading the Chinese industrial structure. Therefore, there are huge practical meanings in analyzing the NEG efficiency of other countries, such as OECD countries, and the differences in NEG efficiency between China and these countries to optimize resource allocation and increase the production efficiency of the Chinese new energy industry.

The existing studies focus on the field of energy systems and new energy generation technology [17-19]. In order to reduce the uncertainty of new energy in the process of grid connection, experts and scholars have developed high-efficiency and high-performance renewable energy power generation systems to make photovoltaic, wind, and bioenergy more elastic in the production of electricity, heat, and hydrogen. Wang et al. [20] developed a high-robust battery- interfaced power supply system to play the role of an energy storage device in the microgrid. Zhang and Ruan [21] developed a high-performance two-stage single-phase converter are developed for efficiently and reliably utilizing new energy. Sun et al. have also done a lot of research in the fields of energy Internet [22], DC microgrid [23], energy storage [24], and so on. Some scholars have also argued the negative effects of renewable energy power generation [25], such as the environmental issues caused by the large-scale utilization of photovoltaic. Most of these researches employed the efficiency method to calculate the power generation of new energy or renewable energy. These energy-efficient researches emphasize achieving the same production activities and outputs with less energy input or consumption [26]. Scholars have gradually added environmental protection and other indicators to the evaluation of energy efficiency [27-30].

At present, research on the measurement of energy efficiency includes four categories in general: first, considering energy efficiency factors, studies have ranged from investigating one-factor energy efficiency to the multifactor substitution of general factor energy efficiency $[1,31]$; second, considering the research object, energy efficiency has been studied from the national level to the industry and regional levels $[28,32,33]$. In recent years, Chinese scholars have paid particular attention to regional differences in energy efficiency but have paid less attention to industry differences. Comparatively, the research perspective of foreign scholars is more microscopic: they study energy 
efficiency issues from the perspective of industry or consumption behavior [34-36]. Third, for the measurement method, studies include methods based on the traditional DEA (data envelopment analysis) model, the superefficiency DEA model, and the SFA (stochastic frontier analysis) model [32]. The method of calculating energy efficiency has been gradually enriched. Last but not least, considering the time dimension, there are not only descriptions of short-term energy efficiency focusing on characteristics but also discussion of the long-term evolutionary trend in energy efficiency [35]. All of these studies have expanded the research field of energy efficiency.

However, the NEG efficiency was seldom calculated from the economic angle among those studies. This paper tried to use the SFA to calculate economic efficiency. At present, the installed capacity tends to be growing due to policy support for equipment investments and growth in grid price. In contrast, new energy input (installed capacity) and output (power generation) are employed to measure NEG efficiency from the economic perspective in the context of government support.

Contributions of this study are mainly the following aspects. First, the measurement of efficiency takes the economics of technology and tax policy support into consideration. Second, the input data of new energy (solar, wind, geothermal, and biofuel) during the period from 2006 to 2018 in OECD countries were employed in this study. Third, the influence factors of NEG efficiency were explored from a novel point of view and solutions for increasing the efficiency of new energy grid power generation were presented.

The following part of this paper is prepared as follows. Section 2 presents the literature review. Section 3 includes the methodology. Section 4 depicts the results and empirical analysis, and Section 5 proposes the conclusions and suggestions.

\section{Literature Review}

2.1. Energy Efficiency Research Methods. The research methods adopted by existing literature on energy efficiency are mainly divided into nonparametric and parametric methods [37-39]. The former uses a mathematical programming method to estimate efficiency values, and the representative method is DEA. The latter uses an econometric model to estimate model parameters and efficiency values using statistical methods, and the representative method is SFA.

The DEA method adopts a mathematical programming model to compare the relative efficiency between decisionmaking units (DMUs), and it is widely applied because it does not need to set production functions and unify dimensions [40]. The SFA method determines the functional form of cost and profit or the production relationship between inputs, outputs, and environmental variables and takes into account random error [1]. The advantage of the SFA method is that its estimated frontier is random, including noise, the error term, and exogenous interference. Both the DEA and the SFA methods measure technical efficiency by constructing the production frontier [41]. The technical efficiency is relative, and its values can be compared within the sample but cannot be compared between different samples [42]. The differences between the two approaches are as follows [41-43].

First, the assumptions and model extensions between the DEA and SFA methods are different. The assumptions of the SFA method need to simultaneously consider the actual form of the production function as well as technical inefficiency distribution, which makes it difficult to extend the model. The DEA approach does not consider the actual form of the production function, its model is easy to expand, and there are many DEA extension models.

Second, the methods of constructing production frontiers between DEA and SFA methods are different. The SFA method uses a production function and random disturbance term to construct a random production frontier, while the DEA method uses one or more DMUs as technical effective points based on the DMU input-output data and then constructs a production frontier. For panel data, the SFA method constructs one unified production frontier based on the data of all periods, while the DEA method constructs one production frontier per period. The SFA method estimates each parameter value with the maximum likelihood method and then uses the conditional expectation of the technical inefficiency as the technical efficiency value; the efficiency value of the DMUs will not be 1 . The DEA calculates the efficiency value through linear programming, and at least one DMU will have an efficiency value of 1 .

Third, the interpretation and treatment methods of actual output differ between the DEA and the SFA models. The SFA model takes the impacts of random factors on the output into consideration, and the output covers three categories: the production function, random factors, and technical inefficiency. The DEA model attributes the actual output less than the frontier output to technical efficiency, ignoring the impacts of random factors on the output.

Fourth, the DEA and SFA models use different methods of analyzing the influencing factors. When calculating the technical efficiency and analyzing the influencing factors, the SFA model only needs to express the technical inefficiency term as the linear form of the influencing factors whose parameters can be estimated in the original model. The DEA model estimation of the parameters of the influencing factors needs to be divided into two steps: the first is to calculate technical efficiency; the second is to take the technical efficiency as the dependent variable and the influencing factor as the independent variable and applies the binary discrete model to analyze its relationship. Therefore, the SFA model is more convenient for analyzing the influencing factors.

Finally, the robustness of the results between the DEA and SFA models is different. The SFA model employs the maximum likelihood estimation method to measure the parameters of influence factors and then adopts the conditional expectation to measure the DMU technical efficiency; therefore, the results are more effective because of not being affected by outliers. The DEA model constructs the frontier through technically effective samples, and if there 
are outliers in the samples, the results will be strongly affected.

As shown in Figure 2, the estimation results will be different when technical efficiency is measured using the SFA or the DEA model. Considering the above analysis as well as the features of the new energy industry, this study will adopt the Battese and Coelli [44] model of SFA to study the technical efficiency of the new energy industry and apply the Cobb-Douglas function to explore the influence factors of energy efficiency.

2.2. Evaluating the New Energy Efficiency. The studies on new energy efficiency focus on two aspects in the existing literature: production and power generation efficiency.

Xin and Li [45] used the DEA model to examine and compare the input-output efficiency in wind energy, nuclear energy, and biomass energy in China and concluded that, in China, the distribution and management efficiency of nuclear power is higher than that of wind energy and biomass energy. Wang et al. [46] adopted the DEA model to study Chinese new energy efficiency. They depicted the new energy efficiency in development and utilization from 2009 to 2013 by decomposing the input-output efficiency. However, the literature mainly focuses on a specific variety of new energy. For example, Sueyoshi and Goto [47] compared the generation efficiency of solar power stations between the USA and Germany through the DEA method. Gökgöz and Erkul [48] constructed an economic evaluation model of renewable resources development and utilization based on the superefficiency DEA method. On the one hand, previous studies have formed a set of methods in the analysis of power generation efficiency, especially in coal power generation. These methods first select investment, labor, coal consumption, and installed capacity as input indicators and electricity generation as output indicators. Then, it employed the DEA model, SFA model, or Malmquist productivity index to measure the technical efficiency of coal power generation $[43,49,50]$.

On the other hand, there are few studies focusing on the measurement of new energy generation efficiency. Using the Bootstrap-DEA method and panel Tobit model, Li [51] examined the overall efficiency of new energy generation in 23 countries. Cai et al. [52] evaluated the new energy and renewable energy power generation performance of G8 and BRIC. They concluded that the power generation performance of developed countries is more massive. Still, the growth rate of developing countries is higher, indicating that the performance of new energy generation in developing countries is also gradually improving. The power generation performance of countries with rich resource endowments is lower than that of countries with insufficient resources, indicating that the performance of new energy generation is not positively correlated with resource endowments. Countries with low resource endowments improve the power efficiency of existing resources through technology investment. Technological progress and $\mathrm{R} \& \mathrm{D}$ investment play a prominent part in improving the performance of new energy generation. The above literature adds up the installed capacity of new energy and pays attention to the overall effect but ignores the uniqueness of different types of new energy. Xin and Li [45] adopted the DEA model to examine the efficiency of Chinese new energy companies. Shi et al. [53] used a four-stage DEA to measure the efficiency of new energy enterprises and concluded that the efficiency of the nonpower generation industry is increasing annually, while the efficiency of the power generation industry is unchangeable.

\subsection{The Production Efficiency of New Energy and the Influence} Factors. Lots of studies focus on the efficiency of industries or companies, and the factors examined include government policies [54, 55], economics [56], technical innovation [33], urbanization [57, 58], and education level [59]. The existing studies neither focus on these variables together nor the new energy industry. Here, variables were selected according to the operating conditions of the new energy industry. It examines the impacts of external factors (government policies, economic level, technical innovation, urbanization, and education level) on the development of the new energy industry as well as on technical efficiency.

2.3.1. Government Policies. Government policies usually refer to industry-related policies, such as planning policies, technological policies, and development policies, which mainly aim at complementing imperfect market mechanisms, achieving better resource distribution, and protecting and supporting the development of emerging industries. In particular, government policies generate crucial effects on the efficiency of the new energy industry. The government has guaranteed relatively greater support and subsidies for the new energy industry. These government subsidies mainly include financial allocations, discounts, tax rebates, and free nonmonetary property $[54,60]$. Government subsidies can primarily help the industry and enterprises to improve corporate performance through the following three channels.

First, the government provides subsidies for the R\&D activities of enterprises to encourage innovation. Meanwhile, the government strengthens the protection of intellectual property and patents, which can significantly reduce the occurrence of enterprises plagiarizing others' R\&D achievements. Furthermore, government subsidies also help to support enterprises' investments in $\mathrm{R} \& \mathrm{D}$ activities and production costs. This increase in enterprises' $R \& D$ funds will encourage them to better conduct technical innovation and thus increase the efficiency of the entire industry.

Second, government subsidies can improve the quality of production factors purchased by enterprises [61, 62]. Highquality capital and labor input can result in stronger output capacity [63]. It can also concurrently promote the formation of economies of scale and allow enterprises to achieve a high degree of concentration in their development, design, manufacturing, marketing, and management activities. With the same inputs, the output capacity of enterprises is enhanced. Government subsidies improve the 



Figure 2: The comparison between SFA and DEA.

efficiency of enterprises and further promote the efficiency of the entire industry.

Third, government subsidies are provided for certain emerging and weak industries to help them achieve healthy and sustainable development, especially when these industries are deeply involved in people's livelihoods and the national economy. The high-tech new energy industry is characterized by a long development cycle and high investment costs. The subsidies for the new energy industry by various governments are mainly in the following forms: financial support for newly established new energy enterprises, price subsidies for new energy products, and subsidies for customers purchasing new energy products.

2.3.2. Economic Level. The regional economic level directly affects the development of the local new energy industry $[64,65]$. Infrastructure, facilities, and fixed assets require a large number of funds [56]. Usually, economically developed regions invest more in the new energy industry because they possess a more scientific management ideology and highly qualified employees and are more open-minded [66]. In a sense, regional economy fuels industrial development and supports resource-related industrial new energy activities.

2.3.3. Technical Innovation. Technical innovation is the fundamental factor that affects technological efficiency. Theoretically, the level of technological research (as the core of technological innovation) positively affects technological efficiency. Fan et al. [67] used panel data as samples and applied the stochastic frontier approach to examine the relationship of the R\&D level and technological efficiency in the Chinese high-tech industry and concluded that the R\&D level affects technological efficiency positively and significantly [68]. When examining whether the R\&D level significantly affects efficiency, the first step is to study financial investments in $\mathrm{R} \& \mathrm{D}$ activities because financial investments can be used to purchase skilled labor and R\&D equipment or to cultivate technical innovation among the R\&D team [69]. The amount of financial investment in R\&D activities can reflect whether the enterprises' strategic management values
R\&D [70]. Government subsidies for R\&D activities in the new energy industry indicate that the government has focused on R\&D innovation in the industry. The level of R\&D can stimulate the technological progress of the new energy industry. In general, the greater focus an enterprise devotes to $R \& D$, the greater its $R \& D$ input will be and the greater its resulting output efficiency will be. In other words, a higher level of R\&D will inevitably result in higher efficiency of the new energy industry.

2.3.4. Urbanization. Currently, global environmental pollution tends to be serious. In particular, continuous largescale haze weather has had terrible effects on peoples' lives $[71,72]$. Haze forms through the accumulation of pollution from high energy consumption industries and motor vehicle exhaust emissions. Due to the urbanization process, the emissions of industrial and domestic exhaust gases, including sulfur dioxide, soot, and dust, in cities and towns have significantly increased, which has worsened air pollution [73-75]. Among them, the emissions of industrial gases are the main reason for air pollution, which accounts for over $85 \%$ of total emissions. Furthermore, the concentration and rapid growth of nonagricultural industries driven by urbanization are the cause of the increase in industrial gases. Rapid urbanization is accompanied by largescale transportation; increased water supply, drainage, heating, and gas supply; and other types of infrastructure construction. In addition, the construction of infrastructure produces large amounts of dust, sulfur dioxide, carbon dioxide, and other gases, which aggravate the greenhouse effect in the atmosphere. During continuous circular processes, the adverse effects of urbanization on haze become increasingly obvious.

The new energy has lower or zero emissions, which fundamentally solves the two shortcomings of limited resources and environmental pollution from fossil fuels. Under such circumstances, the new energy industry will occupy a large proportion of the urbanization market. Moreover, due to the unbalanced distribution of traditional fossil fuels, they are only suitable for large-scale exploration and centralized utilization. This means that, in larger cities, 
the cost of using fossil fuels is lower, while in small-scale towns and rural areas, the costs are higher. However, new energy is perfectly adaptable to this situation. Moreover, the urban migration will change peoples' consumption behaviors. The average annual energy consumption of the urban population is 3.5 times that of the rural population, and their electricity consumption is three times that of the rural population. However, awareness of energy conservation is increasing in both urban and rural areas. People are becoming more inclined to use new energy. The government also strongly encourages the consumption of new energy. This provides a positive external environment for developing a new energy industry.

2.3.5. Education Level. Human resources play a significant part in motivating the development of the new energy industry. Technical innovation needs abundant human resources. And superior human resource reserves will facilitate the development of the new energy industry as a high-tech strategic new industry $[59,76]$. Technologically skilled human resources are necessary for terms of industrial development, knowledge diffusion, and technical innovation. Technological talents, engineers, and professional personnel are priceless resources in new energy enterprises. They will contribute a lot to better corporate performance in a great sense, and a high percentage of technical personnel will significantly improve corporate efficiency.

\section{Methodology}

\subsection{Data Sources and Description of Variables}

3.1.1. Data Sources. A total of 25 OECD countries are selected as research samples considering the successful development of the industry as well as data availability: Australia, Austria, Belgium, Canada, Denmark, Finland, France, Germany, Greece, Iceland, Ireland, Italy, Japan, South Korea, Mexico, the Netherlands, New Zealand, Norway, Poland, Portugal, Spain, Sweden, Turkey, the United Kingdom, and the United States. The countries without developing geothermal energy or biofuel production have a zero value for the indicators of relevant sources. New energy input is reflected by the indicator of installed capacity. This research discusses solar capacity, installed capacity of wind and geothermal energy, and biofuel production. NEG output is reflected by the indicator of electricity generation. The raw data related to wind, solar, and geothermal energy installed capacity and power generation comes from BP energy [5], the International Geothermal Association [77], and the EPS Global statistical platform [78]. The installed capacity and power generation of biofuel data are from IRENA (the International Renewable Energy Agency) [79]. The data relating to investment capital and R\&D investment in wind, solar, biofuel, and geothermal energy come from Bloomberg New Energy Finance [80] and the EPS Global statistical platform. The data for labor comes from IRENA and Bloomberg New Energy Finance. The data for influencing factors such as government policies, the economic level, the urbanization rate, and education level comes from the World Bank, Bloomberg New Energy Finance, and the EPS Global statistical platform. In summary, all data from international research and statistical institutions are shown in Table 1.

3.1.2. Description of Variables. The output is reflected by electricity generation from the new energy source. The input is represented by installed capacity (E) (includes solar, wind, geothermal (geo), biofuel (bio)), capital (K), and labor (L). To be consistent with the method used in previous studies, this paper uses government policies (GP), the economic level (EL), technical innovation (TI), the urbanization rate (UR), and the education level (EDU) as explanatory variables of inefficiency. And the natural logarithm of the number of government subsidies is used to indicate government policies, GDP per capita to indicate the economic level, the natural logarithm of $\mathrm{R} \& \mathrm{D}$ funding to indicate technical innovation, the ratio of urban population to total population to indicate urbanization rate, and the ratio of the population with postsecondary education to population over six-yearold to indicate the education level. The descriptive statistics of these variables are displayed and grouped in Table 2.

3.2. Stochastic Frontier Analysis (SFA). Farrell [81] proposed the concepts of technical efficiency and allocative efficiency and constructed a model to evaluate the technical (non) efficiency and scale (non)efficiency of two-factor input and single-factor output. In Figure 3, the $x$-axis is the unit labor input, the $y$-axis is the unit capital input, $\mathrm{CC}^{\prime}$ is the unit cost curve, and OP is the scale expansion curve (constant returns to scale). $\mathrm{UU}^{\prime}$ is a frontier constructed by linear programming with the low input of each sample (L/Y, K/Y). Technical (non)efficiency and allocative (non)efficiency are estimated by the location of the sample point and the frontier UU'.

If the sample is at point $\mathrm{A}$, which is the intersection of $\mathrm{CC}^{\prime}, \mathrm{OP}$, and $\mathrm{UU}^{\prime}$, then the technical efficiency and allocative efficiency are optimal. If the sample is at point $B$, which is on the OP curve but not on the frontier $\mathrm{UU}^{\prime}$, then the allocative efficiency is optimal, but the technical efficiency is not, and technical inefficiency exists. If the sample is at point $\mathrm{D}$, which is on the frontier $\mathrm{UU}^{\prime}$ but not on the scale expansion curve OP, the technical efficiency is optimal, but the allocative efficiency is not, and there is allocative inefficiency. If the sample is at point $\mathrm{E}$, which is neither on the frontier UU' nor on the scale expansion curve OP, then both allocative efficiency and technical efficiency are not optimal, and there is technical and allocative inefficiency. Later, Farrell and Fieldhouse [82] extended the two-factor cost analysis to multifactor cost comparison.

In this study, the production frontier (maximum output observed under given inputs) is calculated and the exogenous variables affecting performance or technical inefficiency are integrated [83]. The error term in the stochastic frontier model has a one-sided component that is capable of calculating the impacts of technical inefficiency and also a traditional random error that can be used to evaluate the 
TABLE 1: The data source.

\begin{tabular}{lr}
\hline Source & Data \\
\hline $\begin{array}{l}\text { Bloomberg New Energy Finance } \\
\text { BP energy }\end{array}$ & $\begin{array}{r}\text { Investment capital and R\&D investment, labor, government policies, the economic level, the } \\
\text { urbanization rate, and education level. } \\
\text { Installed capacity and power generation. }\end{array}$ \\
$\begin{array}{l}\text { EPS Global statistical platform } \\
\text { International Geothermal Association } \\
\text { IRENA (the International Renewable } \\
\text { Energy Agency) }\end{array}$ & $\begin{array}{r}\text { Installed capacity and power generation, investment capital and R\&D investment, government } \\
\text { policies, the economic level, the urbanization rate, and education level. } \\
\text { Installed capacity and power generation. }\end{array}$ \\
Installed capacity and power generation and labor.
\end{tabular}

TABLE 2: Descriptive statistics of variables.

\begin{tabular}{lcccccc}
\hline Variables & Count & Mean & $\begin{array}{c}\text { Std. } \\
\text { dev. }\end{array}$ & Max & Min & Units \\
\hline Electricity & 325 & 21.32 & 32.23 & 246.52 & 0.04 & TWh \\
Solar & 325 & 1.37 & 14.56 & 53.12 & 0.001 & GW \\
Wind & 325 & 22.35 & 49.55 & 172.34 & 0.001 & GW \\
Geothermal & 325 & 0.29 & 1.85 & 3.63 & 0.00 & GW \\
Biofuel & 325 & 1.35 & 55.68 & 310.41 & 0.00 & Mt \\
Capital & 325 & 20.75 & 23.17 & 116.55 & 0.19 & Billion/ \\
& & & & & & dollar \\
Labor & 325 & 27.68 & 61.35 & 361.7 & 0.13 & $\begin{array}{c}\text { Person } \\
\text { GP }\end{array}$ \\
EL & 325 & 14.19 & 7.85 & 21.34 & 6.33 & LN \\
TI & 325 & 8.27 & 5.79 & 12.35 & 5.23 & LN \\
UR & 325 & 8.79 & 12.42 & 23.45 & 1.31 & LN \\
EDU & 325 & 76.51 & 18.35 & 98.57 & 31.53 & $\%$ \\
\hline & 325 & 20.89 & 9.95 & 75.9 & 10.52 & $\%$ \\
\hline
\end{tabular}

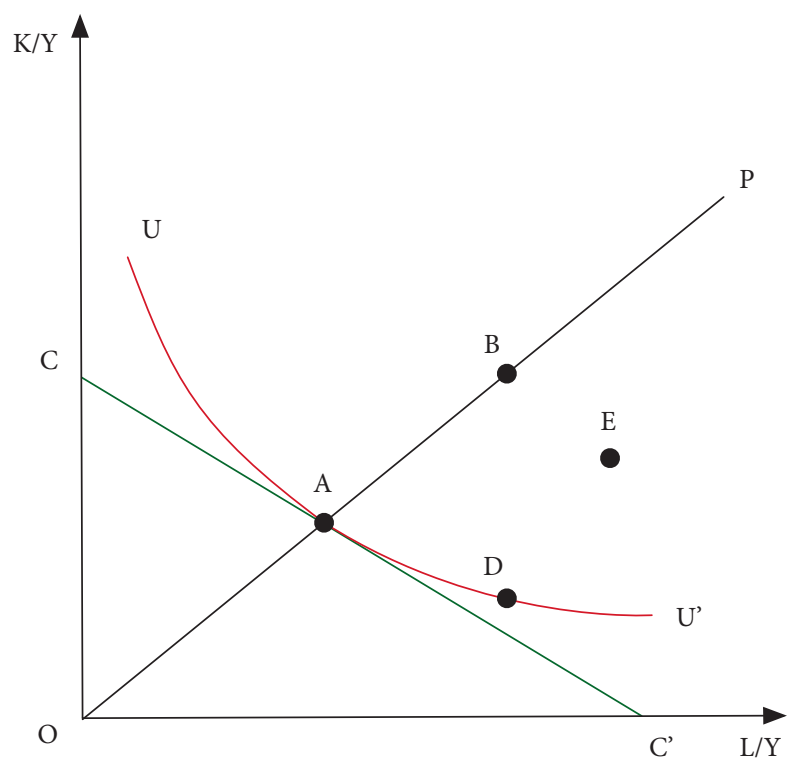

FIGURE 3: The stochastic frontier model.

impacts of measurement error. Here is the production function:

$$
y_{i t}=\alpha+\beta x_{i t}+v_{i t}-u_{i t},
$$

where $y_{i t}$ represents the logarithm of output, $x_{i t}$ represents the vector of the set of inputs, $\alpha$ is a constant, and $\beta$ is the vector of production parameters to be estimated. $v_{i t}$ represents a random error, and $u_{i t}$ is the one-sided error term reflecting inefficiency. Assume that $v_{i t}$ and $u_{i t}$ are independent and that $u_{i t}$ is independent of $x_{i t}$. Various distributions are presented for the distribution of $u_{i t}$. Two methods are employed to link determinants of efficiency in the stochastic frontier model.

When using the two-step method, the inefficiency is estimated, which does not consider all exogenous influence factors in the first step. Then a regression of inefficiency estimates against explanatory variables is developed in the second step. If variables in the production function are correlated with variables in the inefficiency effect components, the estimates of this method are biased $[83,84]$.

When using the one-step method, relationships in the production process and factors causing inefficiency can be estimated [84]. The inefficiency effects component of the frontier model contains explanatory variables affecting technical inefficiency. Here is the inefficiency effects model:

$$
\begin{aligned}
& u_{i t}=\gamma z_{i t}+w_{i t}, u_{i t}>0, \\
& u_{i t} \sim i, i, d . \infty N\left(\gamma z_{i t}, \sigma_{u}^{2}\right), \\
& w_{i t} \sim i, i, d . \infty N\left(-\gamma z_{i t}, \sigma_{u}^{2}\right), \\
& v_{i t} \sim i, i, d . \infty N\left(0, \sigma_{v}^{2}\right),
\end{aligned}
$$

where $z_{i t}$ represents the vector of explanatory variables affecting technical inefficiency, $\gamma$ represents the parameter vector of the inefficiency variables, and $w_{i t}$ represents the random components of inefficiency. Equations (1) and (2) are combined to arrive at the empirical SFA model.

$$
y_{i t}=\alpha+\beta x_{i t}+v_{i t}-u_{i t}\left(z_{i t}, \gamma\right)
$$

The Cobb-Douglas functional form and key predictor variables were mentioned earlier to construct a general model for NEG $[43,85]$. Initial inputs are represented by the installed capacity of solar, wind, geothermal, and biofuel. Here is the basic production function:

$$
\operatorname{In} y_{i t}=\beta_{0}+\beta_{1} \operatorname{In}(E)+\beta_{2} \operatorname{In}(K)+\beta_{3} \operatorname{In}(L)+v_{i t}-u_{i t},
$$

where $y_{i t}$ refers to the output measured as electricity generation for the $i$ th country in the $t$ th year from the new energy source. The input is represented by installed capacity (E) (including solar, wind, geothermal (geo), and biofuel 
(bio)), capital $(K)$, and labor $(L)$. Other factors also affect the productivity and effectiveness of new energy power. Independent variables in the inefficiency component of the SFA are government policies (GP), the economic level (EL), technical innovation (TI), the urbanization rate (UR), and the education level (EDU), which are employed to reflect the impacts of these characteristics on productivity and effectiveness of new energy power. Here are the inefficiency effects:

$$
\begin{aligned}
u_{i t}= & \gamma_{0}+\gamma_{1}(\mathrm{GP})+\gamma_{2}(\mathrm{EL})+\gamma_{3}(\mathrm{TI})+\gamma_{4}(\mathrm{UR}) \\
& +\gamma_{5}(\mathrm{EDU})+w_{i t} .
\end{aligned}
$$

Equation (4) is a stochastic frontier model of the inputs. Equation (4) can be converted into

$$
\mathrm{TE}_{i, t}=\frac{E[f(x) \exp (v-u)]}{E[(f(x) \exp (v-u) \mid u=0)]},
$$

where $f(\cdot)$ represents the energy demand function from the technical perspective of the certain frontier of inputs, $E(\cdot)$ is the conditional expectation, $\mathrm{TE}_{i t}$ is the energy technical efficiency, $I_{i t}$ refers to the input factors including $E$ and $K$, $O_{i t}$ is the output factor $y$, and $Z_{i t}$ refers to other external factors. Given an output, the deterministic frontier can be used as a benchmark. It regards the excess of real input over the deterministic frontier as excessive input caused by technical inefficiency and takes energy savings through the removal of technical inefficiency as energy conservation potential. Because the practical observation error of the SFA model is a mixed error $\left(u_{i t}+v_{i t}\right)$, the effects of inefficiency could be separate. According to the decomposition method mentioned above, the power generation technical efficiency is as follows:

$$
\begin{aligned}
\mathrm{TE}_{i, t} & =\frac{E[f(x) \exp (v-u)]}{E[(f(x) \exp (v-u) \mid u=0)]} \\
& =\frac{f(x ; \beta) \exp (v)^{*} \exp (-u)}{f(x ; \beta)^{*} \exp (v)}=\exp (-u) .
\end{aligned}
$$

We used Stata 15.1 SE software to solve equation (7).

\section{Results and Empirical Analysis}

Results in Table 3 indicate that there is a correlation between electricity and government policies, the economic level, technical innovation, the urbanization rate, and the education level. It means the selection of nonefficiency variables is appropriate. According to the results in Table 4, the variance inflation factor values of the nonefficiency variables are significantly less than 10 , which indicates no multicollinearity between variables. These results mean that it needs further analyses to explore the relationships among factors.

Results in Table 5 show that the coefficient of GP is -0.104 , and it passed the significance test at the $1 \%$ level, which means that government policies have a significant extremely positive effect on NEG efficiency. Government subsidies can greatly promote improved technological efficiency. The new energy industry policies of all governments have a significantly positive effect on improvements in the technological efficiency of the industry and play a positive part in encouraging the development of the new energy industry. Take Germany as an example. In the middle and late 1980s, solar and wind power generation started in Germany, and biofuel power generation started in the 1990s. In 2018, renewable energy accounted for $36 \%$ of total electricity generation in Germany, an increase of $21 \%$ in ten years. Wind power plants (especially onshore power plants) will generate about $27.4 \%$ of Germany's total power generation in 2020. The rapid development of new energy in Germany has benefited from the policy of "replacement of coal power."

The coefficient of EL is -0.508 , and it passed the significance test at the $10 \%$ level, which means that the efficiency of NEG in economically developed regions is higher. Countries with higher economic levels usually provide policy and capital support for R\&D supporting renewable technology. Citizens in these countries desire a better environment, which may motivate the government to improve NEG.

The coefficient of TI is -3.108 , and it passed the significance test at the $5 \%$ level, indicating a positive correlation between technical innovation and NEG efficiency. The new energy industry is typically technology-intensive, and its production and operational activities highly depend on professional technologies and equipment. Furthermore, the production efficiency level is closely related to the independent R\&D of core technologies. The more important the industry attaches to technical innovation, the greater the investments in independent $\mathrm{R} \& \mathrm{D}$ and the more obvious the effects of the improvement of the industry's technological efficiency. Therefore, the R\&D investment level reflects both the industry's financial strength and its overall technical strength. It is worth mentioning that the current photovoltaic power generation technology continues to improve, and the cost continues to drop, making it possible to establish a large-scale photovoltaic power generation base in the future.

The coefficient of UR is 5.244, and it passed the significance test at the $10 \%$ level, indicating a negative correlation between urbanization rate and NEG efficiency. Urbanization has resulted in sharp increases in energy consumption. Data of the Development Research Center of the State Council [86] show that every 1\% growth in urbanization rate produces approximately 60 Mtce. of consumption. Coal-related energy generation is relatively stable. NEG will not occupy a dominant position soon in China [87], but the rapid development of new energy is an inevitable trend in the context of "carbon neutrality." The growing urbanization rate results in the lack of capital and a decrease in government subsidies for new energy in China [58], making it more difficult to achieve higher NEG efficiency [57]. If the storage technology or the creation of largescale urban distributed power generation systems cannot make significant breakthroughs, the continuous urban development will ruin the availability of land for NEG.

The coefficient of EDU is -2.351, and it passed the significance test at the $5 \%$ level. It indicates a positive 
TABLE 3: Correlation analysis of variables.

\begin{tabular}{|c|c|c|c|c|c|c|}
\hline Variables & Electricity & GP & EL & TI & UR & EDU \\
\hline Electricity & 1 & & & & & \\
\hline $\mathrm{GP}$ & $0.253^{*}$ & 1 & & & & \\
\hline EL & 0.051 & -0.165 & 1 & & & \\
\hline $\mathrm{TI}$ & $0.199^{* *}$ & 0.255 & 0.125 & 1 & & \\
\hline UR & -0.231 & 0.065 & $0.05^{*}$ & 0.07 & 1 & \\
\hline EDU & 0.123 & $0.038^{* *}$ & 0.117 & $0.14^{* * *}$ & 0.27 & 1 \\
\hline
\end{tabular}

Note. ${ }^{* * *},{ }^{* *}$, and ${ }^{*}$ Significant at $1 \%, 5 \%$, and $10 \%$ levels, respectively.

TABLE 4: VIF test.

\begin{tabular}{lll}
\hline Variables & VIF & $1 /$ VIF \\
\hline UR & 2.63 & 0.380 \\
EL & 2.25 & 0.444 \\
EDU & 1.83 & 0.546 \\
GP & 1.52 & 0.658 \\
TI & 1.18 & 0.894 \\
Mean VIF & 1.88 & \\
\hline
\end{tabular}

TABLE 5: Results of stochastic frontier models.

\begin{tabular}{lccc}
\hline Variables & Coefficient & Std. dev. & $p$-value \\
\hline Constant & 5.321 & 1.441 & 0.107 \\
Solar & $8.012^{* * *}$ & 3.015 & 0.001 \\
Wind & $2.105^{*}$ & 1.015 & 0.069 \\
Geothermal & $0.432^{*}$ & 1.079 & 0.053 \\
Biofuel & $5.206^{*}$ & 2.305 & 0.073 \\
Capital & $0.574^{* *}$ & 2.911 & 0.029 \\
Labor & 4.172 & 5.103 & 0.126 \\
\hline Determinants of inefficiencies & & & \\
GP & $-0.104^{* * *}$ & 0.558 & \\
EL & $-0.508^{*}$ & 0.917 & 0.001 \\
TI & $-3.108^{* *}$ & 2.013 & 0.085 \\
UR & $5.244^{*}$ & 4.795 & 0.035 \\
EDU & $-2.351^{* *}$ & 3.564 & 0.065 \\
Gamma & $0.247^{* * *}$ & 0.145 & 0.049 \\
LR & 85.355 & & 0.001 \\
\hline
\end{tabular}

Note. ${ }^{* * *},{ }^{* *}$, and ${ }^{*}$ Significant at $1 \%, 5 \%$, and $10 \%$ levels, respectively.

correlation between education level and NEG efficiency. High education levels generate high technical efficiency. In other words, the development of education can help to improve the efficiency of the new energy industry.

According to equation (7), the average technical efficiencies of new energy (wind, biofuel, solar, and geothermal) generation from 2006 to 2018 are $0.808,0.645,0.581$, and 0.395 , respectively, in Table 6. Figure 4 shows that, from 2006 to 2018, the wind, biofuel, and solar generation efficiency increased but geothermal efficiency decreased.

As shown in Figure 5, Canada, Germany, the USA, Iceland, and Mexico realized the top NEG efficiency, but Italy, Japan, and the UK fell behind due to their excessive dependence on foreign energy and unclear energy policies because of political turmoil in Greece. The UK ranked 20th because fossil fuels were used as the main energy source, which makes it difficult to improve the efficiency by NEG in a short period. Since 2012, due to progress in power generation and storage technology, the NEG efficiency has been rising. Finally, these results could lead to some implications for China in developing new energy industries. With the increasing energy demand, the Chinese government should focus on energy conservation and environmental aspects and release related policies to fuel the development of new energy power generation. For instance, the UK government puts new energy at the top of its green economy policy. 
TABLE 6: The efficiency of four types new energy generation.

\begin{tabular}{lllcl}
\hline Year & Solar & Wind & Biofuel & Geothermal \\
\hline 2006 & 0.465 & 0.648 & 0.401 & 0.465 \\
2007 & 0.475 & 0.653 & 0.451 & 0.445 \\
2008 & 0.482 & 0.661 & 0.547 & 0.434 \\
2009 & 0.523 & 0.685 & 0.562 & 0.421 \\
2010 & 0.551 & 0.782 & 0.614 & 0.414 \\
2011 & 0.576 & 0.789 & 0.648 & 0.382 \\
2012 & 0.589 & 0.795 & 0.691 & 0.377 \\
2013 & 0.595 & 0.812 & 0.711 & 0.371 \\
2014 & 0.623 & 0.915 & 0.753 & 0.365 \\
2015 & 0.637 & 0.923 & 0.803 & 0.361 \\
2016 & 0.655 & 0.932 & 0.811 & 0.355 \\
2017 & 0.687 & 0.941 & 0.853 & 0.347 \\
2018 & 0.695 & 0.964 & 0.645 & 0.392 \\
Mean & 0.581 & 0.808 & 0.395 \\
\hline
\end{tabular}
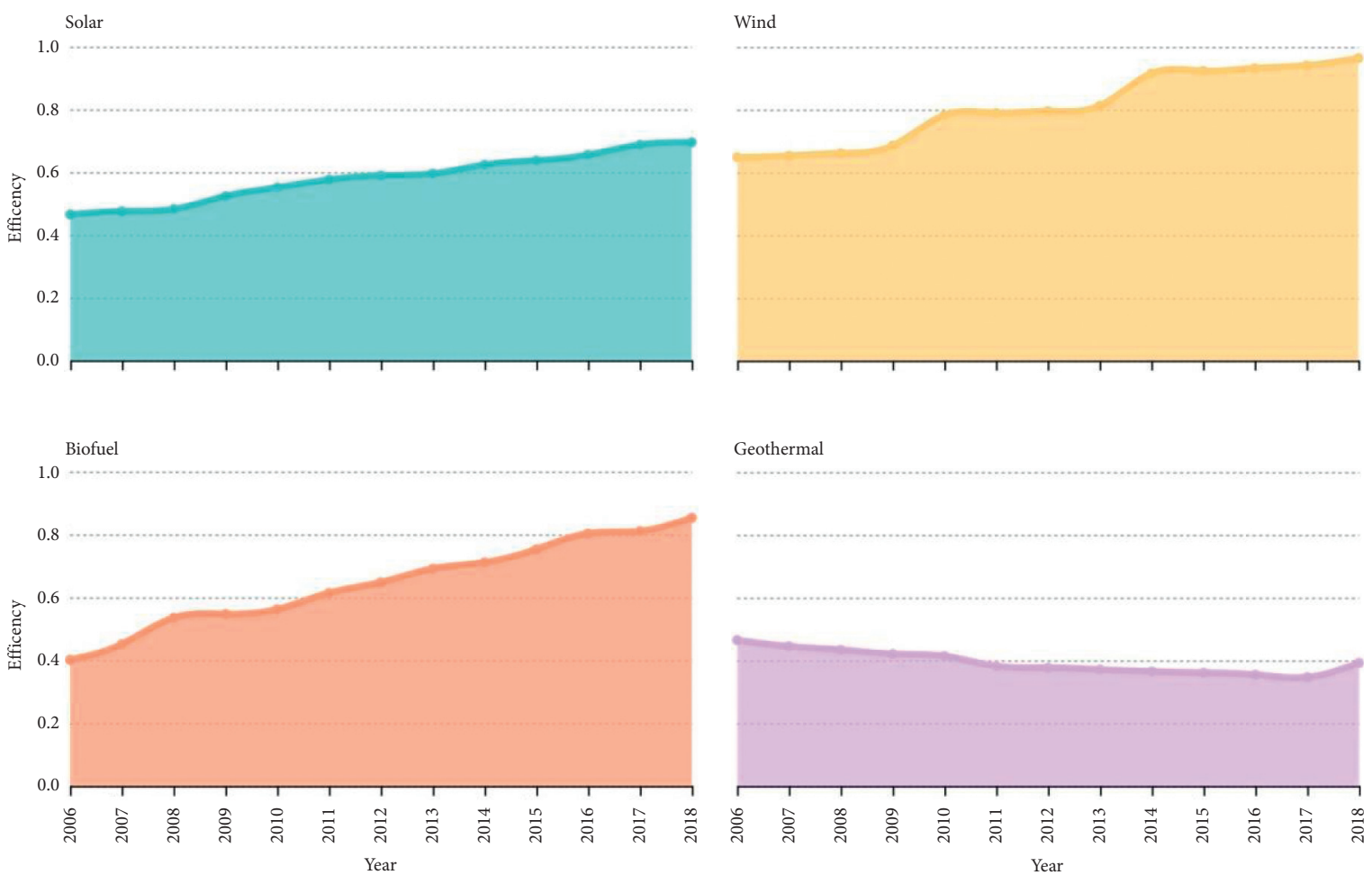

Figure 4: The efficiency of four types of new energy generation.

Germany has the largest solar power plant globally, and the government encourages households to install solar power generation equipment. Japanese government attaches great importance to emission reduction and focuses on demonstrating the social impact of the green economy through daily consumption behavior. 


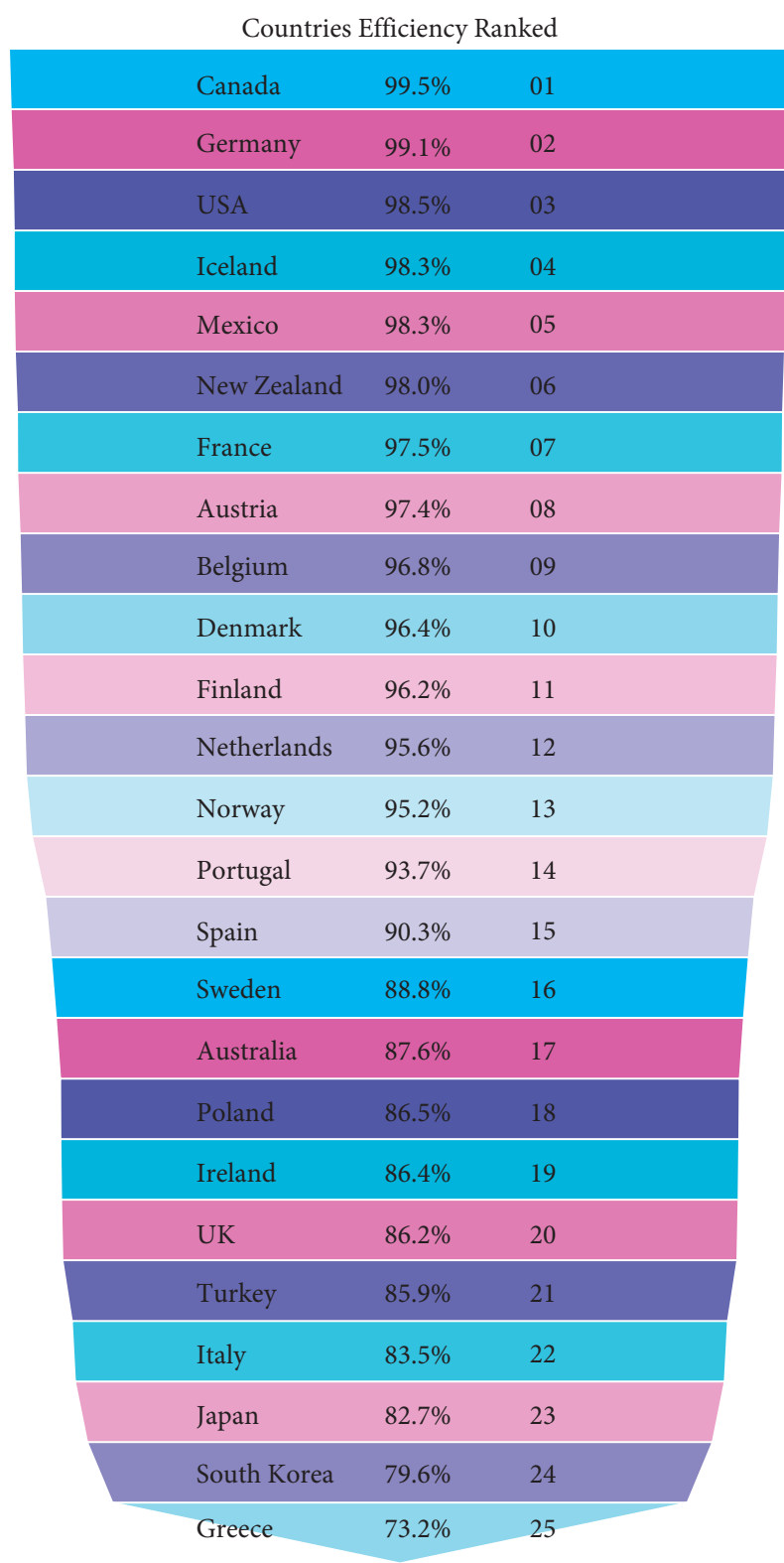

FIgURE 5: The energy efficiency of NEG in OECD countries.

\section{Conclusions and Implications}

5.1. Conclusions. The existing literature focuses on driving factors of NEG performance evaluation, carbon emission reduction efficiency, and improving power generation efficiency at the technical level. For example, Cai et al. [52] evaluated the performance of new energy generation in G8 and BRIC countries. It shows that the power generation performance of countries rich in the new energy is lower than that of resource-poor countries. The total performance of new energy generation in developed countries is better than that in developing countries, while the growth rate is lower than that in developing countries. In comparison, the SFA method from an input-output perspective is applied. The power generation efficiency of new energy is measured at the economic level, and the influence factors are examined in this paper.

Based on early analysis, the following results are obtained. Government policies have a positive relationship with NEG efficiency, which means that they can promote improved NEG efficiency. The economic level has a positive relationship with NEG efficiency, which means that countries with a high per capita income have high NEG efficiency. Both technical innovation and education level are positively correlated with NEG efficiency. Higher education levels result in higher technical efficiency.

Finally, the urbanization rate is negatively correlated with NEG efficiency, which means that the rise of urbanization can restrict the development of NEG due to competing government financial initiatives. Similarly, Liu and Wei [88] explored the impacts of urbanization rate and factor endowment on carbon emission reduction efficiency. The results indicated a " $U$ " shape relationship between urbanization rate and carbon emission reduction efficiency. Therefore, they argued that the government should distinguish the difference of factor endowment among regions to control the process of urbanization in energy-oriented provinces based on the establishment of the carbon market.

5.2. Implications. We provide some suggestions for the development of NEG from the perspectives of government policy, technical innovation, urbanization rate, and education level as follows.

5.2.1. Formulate Preferential Government Policies for the New Energy Industry. First, new energy development and utilization should take the improvement of power generation efficiency as the primary standard and avoid excessive policy incentives only acting on investment areas such as the increase of installed capacity. The government policy should increase the power generation per unit of installed capacity and the cooperation between the expansion of installed capacity and the rise in power generation.

Second, improve the supporting policies and measures for the new energy industry. Although some developing countries have already issued a series of supporting policies, these policies are not always effectively implemented or applied. This situation is caused by the fact that new energy companies lack flexibility and sensitivity to policies, and so these policies have no opportunity to benefit these new energy companies. Furthermore, the formulation of some policies is too vague. Through the improvement of relevant laws, systems, and industrial policies, governments should be able to realize the final aim of guaranteeing the supply of necessary funds, talent, and material resources for the development of the new energy industry.

Last, provide more tax and financial benefits. Favorable financial and tax policies can generate direct and prominent effects on the new energy industry during its developmental period. Relevant departments should focus on rewarding and subsidizing technical innovation among enterprises by 
establishing tax-exempt items. Moreover, governments should provide convenient financing for new energy enterprises that includes offering certain preferential treatment for interest expenses and providing financial support for new energy technology innovation projects. While slashing financial and tax subsidies for traditional industries, governments should increase subsidies for the new energy industry and strongly support its development.

5.2.2. Improve the Technical Innovation System of the New Energy Industry. First, technological progress produces a significant effect on NEG in countries, which means that the technological processes can promote NEG. Besides, the impact of technological progress on the efficiency of NEG varies in countries, and technological progress plays a significant part in increasing the efficiency of NEG in countries in the period of the fast development of new energy, such as Italy and Japan. For countries where the development of new energy has entered a mature stage, such as Germany and France, the driving force of technological progress on the efficiency of NEG has been weakened. Therefore, for China, which is in the exploration period of the development of new energy, it should promote breakthroughs of critical technologies continuously and orderly to ensure the investment of new energy. Meanwhile, policy-makers should establish a long-term, national, and efficient technology transformation channel so that the investment of new energy can be applied more effectively and faster in the electric power field.

Second, promote the progress of new energy equipment technology. The production and innovation of technical equipment are the embodiment of core technological progress for the new energy industry and the key to transforming new energy technology into actual production. Therefore, developing countries should emphasize guiding and promoting progress in the new energy equipment technology to establish the foundational equipment for the popularization and application of new energy technologies.

Finally, establish a platform for new energy technology innovation. Overall improvement of the technological level of the new energy industry requires a strong innovation platform as support. Its main approach is to rely on large enterprises, research institutes, and universities to build a national energy technology innovation platform. The establishment of the innovation platform can provide favorable conditions for R\&D, the upgrading of overall industrial technology, and acceleration of the production, application, and popularization of the technology in various fields. This technological innovation cannot remain solely at the research level since it must better serve social production activities.

5.2.3. Design New Forms of Urbanization. First, take a path towards urbanization based on overall planning and scientific distribution across urban and rural areas and avoid the overconcentration of urban populations. Governments must abandon the concept of "metropolitanism" represented by blind urban expansion and implement the regional integration of urban agglomeration and reasonable zoning of city functions, as this can effectively alleviate the serious ecological burden of the urban environment.

Second, optimize and upgrade the industrial structure, resolutely abandon outdated high-energy-consuming industries, and vigorously develop the green economy. When green production and green consumption become an important component or even the mainstream of urban economic life, the proportion of energy-saving products, renewable energy products, and green buildings will sharply increase. Then, the green industry will become an important channel of employment and an economic growth engine.

Finally, improve the urban function system and strengthen public participation in environmental governance. Environmental protection requires everyone's participation. Governments must establish and improve relevant legislation, establish environment-related "government performance" and accountability mechanisms, and encourage public participation in the legislation of environmental management. In the process of improving urban service and communication functions, exchange and mutual trust between the public and the government will be realized, and awareness of the urban community and common homeland will be formed, encouraging citizens to work together to address comprehensive urban environmental issues, including haze prevention and control.

5.2.4. Improve the Education Level and Cultivate New Energy Professionals. On the one hand, emphasize the cultivation of technical personnel. Since technical personnel are critical to technical innovation, it is impossible to develop independent innovation competency of the new energy industry without their support and participation in enterprises. To cultivate the technical personnel, it is necessary to establish a rational and reasonable salary system to retain employees. Besides, technical training and learning opportunities should be provided for employees, especially for high-tech professionals. The number of technical personnel for the latest technological $\mathrm{R} \& \mathrm{D}$ and innovation must be continuously increased. This will lay the foundation for the development of the new energy industry.

On the other hand, set up a special platform for the cultivation of professionals. First, developing countries should set up new energy technology R\&D institutions to lead R\&D breakthroughs and the innovation of key technologies in the new energy industry. These institutions should focus on developing core technologies with independent intellectual property rights to provide experimentally and practice sites for new technology professionals. Second, China should actively promote the study and exchange of talent at home and abroad and attract better overseas professionals to come to China and provide valuable suggestions. Concurrently, China should send technologists to study abroad and learn more advanced technologies.

5.3. Future Research Directions. This paper explores the power generation efficiency of new energy from the economic perspective and analyzes the influence factors. 
However, some improvements can be implemented in future research. On the one hand, this study measures the output of new energy generation using a one-dimension indicator. On the other hand, we have not constructed the quantitative indicators for new energy generation policies in countries. These issues will be the research direction for further studies.

\section{Abbreviations}

bio: Biofuel

DEA: Data envelopment analysis

DMU: Decision-making unit

E: Installed capacity

EDU: Education level

EL: Economic level

geo: Geothermal

GP: Government policies

$I_{i t}: \quad$ Input factors

K: $\quad$ Capital

L: $\quad$ Labor

NEG: New energy generation

$O_{i t}: \quad$ Output factor

SFA: Stochastic frontier analysis

TI: Technical innovation

UR: Urbanization rate

VIF: Variance inflation factor

$Z_{i t}: \quad$ Other external factors.

\section{Data Availability}

The data set can be provided upon request to the corresponding author.

\section{Conflicts of Interest}

The authors declare no conflicts of interest.

\section{Acknowledgments}

This work was supported by the Social Science Foundation of Fujian Province (grant no. FJ2021C023).

\section{References}

[1] X.-1. Xu and H. H. Chen, "Examining the efficiency of biomass energy: evidence from the Chinese recycling industry," Energy Policy, vol. 119, pp. 77-86, 2018.

[2] G. Allameh, M. S. Mehrabad, and S. J. Sadjadi, "Pricing decisions in a decentralized biofuel supply chain with RIN mechanism," Energy Sources, Part B: Economics, Planning and Policy, vol. 14, no. 6, pp. 254-273, 2019.

[3] S. Qiao, X.-L. Xu, C. K. Liu, and H. H. Chen, "A panel study on the relationship between biofuels production and sustainable development," International Journal of Green Energy, vol. 13, no. 1, pp. 94-101, 2015.

[4] Chyxx, "The patterns and prospect of world energy," 2018, http://www.chyxx.com/industry/201802/611045.html.

[5] B. P. Dudley, "BP statistical review of world energy 2019: an unsustainable path," 2019.
[6] H. Zameer and Y. Wang, "Energy production system optimization: evidence from Pakistan," Renewable and Sustainable Energy Reviews, vol. 82, pp. 886-893, 2018.

[7] Z. Yang, S. Shao, L. Yang, and Z. Miao, "Improvement pathway of energy consumption structure in China's industrial sector: from the perspective of directed technical change," Energy Economics, vol. 72, pp. 166-176, 2018.

[8] S. D. Musa, T. Zhonghua, A. O. Ibrahim, and M. Habib, "China's energy status: a critical look at fossils and renewable options," Renewable and Sustainable Energy Reviews, vol. 81, pp. 2281-2290, 2018.

[9] Y. Zhao and C. X. Suo, "Existing problems and countermeasures in the development of China's biomass energy industry," Advanced Materials Research, vol. 609, pp. 441-447, 2013.

[10] N. Yoshino and F. Taghizadeh-Hesary, "Alternatives to private finance: role of fiscal policy reforms and energy taxation in development of renewable energy projects," in Financing for Low-Carbon Energy Transition: Unlocking the Potential of Private Capital, V. Anbumozhi, K. Kalirajan, and F. Kimura, Eds., Springer Singapore, Singapore, pp. 335-357, 2018.

[11] M. Mazzucato and G. Semieniuk, "Financing renewable energy: who is financing what and why it matters," Technological Forecasting and Social Change, vol. 127, pp. 8-22, 2018.

[12] X. L. Xu, C. Shun, Y. Li, and N. Zhou, "The effects of environmental management and debt financing on sustainable financial growth in the tourism industry," SAGE Open, vol. 10, pp. 1-12, 2020.

[13] Z. Liu, "China's strategy for the development of renewable energies," Energy Sources, Part B: Economics, Planning and Policy, vol. 12, no. 11, pp. 971-975, 2017.

[14] R.-D. Chang, J. Zuo, Z.-Y. Zhao, G. Zillante, X.-L. Gan, and V. Soebarto, "Evolving theories of sustainability and firms: history, future directions and implications for renewable energy research," Renewable and Sustainable Energy Reviews, vol. 72, pp. 48-56, 2017.

[15] X. Song, T. Xiang, J. Mo, and C. Liu, "Two-leveled allocation mechanism based on regional comparison in China's power sector," Energy Sources, Part B: Economics, Planning and Policy, vol. 13, no. 4, pp. 211-217, 2018.

[16] X. L. Xu, H. H. Chen, and R. R. Zhang, "The impact of intellectual capital efficiency on corporate sustainable growthevidence from smart agriculture in China," Agriculture, vol. 10, p. 199, 2020.

[17] N. Onat and H. Bayar, "The sustainability indicators of power production systems," Renewable and Sustainable Energy Reviews, vol. 14, no. 9, pp. 3108-3115, 2010.

[18] X. L. Xu, H. H. Chen, Y. Feng, and J. Tang, "The production efficiency of renewable energy generation and its influencing factors: evidence from 20 countries," Journal of Renewable and Sustainable Energy, vol. 10, pp. 25901-25911, 2018.

[19] X.-L. Xu, C. Sun, and H. H. Chen, "How diversified fuel-fired power enterprises keep their competitive advantages to reach sustainable development," Environmental Progress \& Sustainable Energy, vol. 38, no. 1, pp. 137-142, 2019.

[20] R. Wang, Q. Sun, W. Hu, Y. Li, D. Ma, and P. Wang, "SoCbased droop coefficients stability region analysis of the battery for stand-alone supply systems with constant power loads," IEEE Transactions on Power Electronics, vol. 36, no. 7, pp. 7866-7879, 2021.

[21] L. Zhang and X. Ruan, "Control schemes for reducing second harmonic current in two-stage single-phase converter: an overview from DC-bus port-impedance characteristics," IEEE 
Transactions on Power Electronics, vol. 34, no. 10, pp. 10341-10358, 2019.

[22] Q. Sun, R. Han, H. Zhang, J. Zhou, and J. M. Guerrero, “A multiagent-based consensus algorithm for distributed coordinated control of distributed generators in the energy internet," IEEE Transactions on Smart Grid, vol. 6, no. 6, pp. 3006-3019, 2015.

[23] R. Wang, Q. Sun, P. Tu, J. Xiao, Y. Gui, and P. Wang, "Reduced-order aggregate model for large-scale converters with inhomogeneous initial conditions in dc microgrids," IEEE Transactions on Energy Conversion, vol. 36, no. 3, pp. 2473-2484, 2021.

[24] E. An, Q. Sun, and D. Ma, "Research on integrated energy regional trading strategy based on cooperative game," in Proceedings of the Chinese Control And Decision Conference (CCDC), pp. 6210-6215, Nanchang, China, June 2019.

[25] K. Kaygusuz, "Environmental impacts of the solar energy systems," Energy Sources, Part A: Recovery, Utilization, and Environmental Effects, vol. 31, no. 15, pp. 1376-1386, 2009.

[26] F. G. Adams and P. Miovic, "On relative fuel efficiency and the output elasticity of energy consumption in Western Europe," The Journal of Industrial Economics, vol. 17, no. 1, pp. 41-56, 1968.

[27] X. Wang, L. Chen, C. Liu, Y. Zhang, and K. Li, “Optimal production efficiency of Chinese coal enterprises under the background of de-capacity-Investigation on the data of coal enterprises in Shandong Province," Journal of Cleaner Production, vol. 227, pp. 355-365, 2019.

[28] K. Li and B. Lin, "How to promote energy efficiency through technological progress in China?" Energy, vol. 143, pp. 812821, 2018.

[29] K. Li and B. Lin, "The efficiency improvement potential for coal, oil and electricity in China's manufacturing sectors," Energy, vol. 86, pp. 403-413, 2015.

[30] K. Li and B. Lin, "Metafroniter energy efficiency with $\mathrm{CO}_{2}$ emissions and its convergence analysis for China," Energy Economics, vol. 48, pp. 230-241, 2015.

[31] X. L. Xu, H. H. Chen, Y. Li, and Q. X. Chen, "The role of equity balance and executive stock ownership in the innovation efficiency of renewable energy enterprises," Journal of Renewable and Sustainable Energy, vol. 11, no. 5, pp. 5590155911, 2019.

[32] H. Chowdhury, T. Chowdhury, M. Thirugnanasambandam et al., "A study on exergetic efficiency vis-à-vis sustainability of industrial sector in Bangladesh," Journal of Cleaner Production, vol. 231, pp. 297-306, 2019.

[33] C. Miao, D. Fang, L. Sun, Q. Luo, and Q. Yu, "Driving effect of technology innovation on energy utilization efficiency in strategic emerging industries," Journal of Cleaner Production, vol. 170, pp. 1177-1184, 2018.

[34] L. Sagbansua and F. Balo, "Decision making model development in increasing wind farm energy efficiency," Renewable Energy, vol. 109, pp. 354-362, 2017.

[35] D. Laslett, C. Carter, C. Creagh, and P. Jennings, "A largescale renewable electricity supply system by 2030: solar, wind, energy efficiency, storage and inertia for the South West Interconnected System (SWIS) in Western Australia," Renewable Energy, vol. 113, pp. 713-731, 2017.

[36] M. Matosović and Ž. Tomšić, "Modeling energy efficiency investment choices - a case study on Croatia's residential sector," Energy Sources, Part B: Economics, Planning and Policy, vol. 13, pp. 311-319, 2018.

[37] B. Lin and H. Zhao, "Technology gap and regional energy efficiency in China's textile industry: a non-parametric meta- frontier approach," Journal of Cleaner Production, vol. 137, pp. 21-28, 2016.

[38] B. Lin and K. Du, “Technology gap and China's regional energy efficiency: a parametric metafrontier approach," Energy Economics, vol. 40, pp. 529-536, 2013.

[39] D. Y. Liu, C. R. Chiu, and J. L. Liou, "Environmental performance measurement with technology heterogeneity: crossregion evidence," Energy Sources, Part B: Economics, Planning and Policy, vol. 12, no. 3, pp. 199-206, 2017.

[40] A. Azadeh, M. S. Amalnick, S. F. Ghaderi, and S. M. Asadzadeh, "An integrated DEA PCA numerical taxonomy approach for energy efficiency assessment and consumption optimization in energy intensive manufacturing sectors," Energy Policy, vol. 35, no. 7, pp. 3792-3806, 2007.

[41] H. W. Lampe and D. Hilgers, "Trajectories of efficiency measurement: a bibliometric analysis of DEA and SFA," European Journal of Operational Research, vol. 240, no. 1, pp. 1-21, 2015.

[42] F. A. Madau, "Technical and scale efficiency in the Italian citrus farming: comparison between SFA and DEA approaches," Agricultural Economics Review, vol. 16, pp. 15-27, 2015.

[43] R. Arsad, Z. Isa, and S. Nabilah Mohd Shaari, "Estimating efficiency performance of decision-making unit by using SFA and DEA Method: a cross-sectional data approach," International Journal of Engineering \& Technology, vol. 7, no. 4, pp. 25-31, 2018.

[44] G. E. Battese and T. J. Coelli, "Frontier production functions, technical efficiency and panel data: with application to paddy farmers in India," International Applications of Productivity and Efficiency Analysis, vol. 45, pp. 149-165, 1992.

[45] Y. H. Xin and X. X. Li, "Technical efficiency and its affect factors research of Chinese new energy listed companies," Technoeconomics \& Management Research, vol. 9, pp. 14-19, 2013.

[46] Q. Wang, Y. Hang, L. Sun, and Z. Zhao, "Two-stage innovation efficiency of new energy enterprises in China: a nonradial DEA approach," Technological Forecasting and Social Change, vol. 112, pp. 254-261, 2016.

[47] T. Sueyoshi and M. Goto, "Measurement of returns to scale on large photovoltaic power stations in the United States and Germany," Energy Economics, vol. 64, pp. 306-320, 2017.

[48] F. Gökgöz and E. Erkul, "Investigating the energy efficiencies of European countries with super efficiency model and super SBM approaches," Energy Efficiency, vol. 12, pp. 601-618, 2019.

[49] S. Toshiyuki and G. Mika, "Efficiency-based rank assessment for electric power industry: a combined use of Data Envelopment Analysis (DEA) and DEA-Discriminant Analysis (DA)," Energy Economics, vol. 34, pp. 634-644, 2012.

[50] C. Woo, Y. Chun, D. Chung, H. Seo, and S. Hong, "The static and dynamic environmental efficiency of renewable energy: a Malmquist index analysis of OECD countries," Renewable and Sustainable Energy Reviews, vol. 47, pp. 367-376, 2015.

[51] S. L. Li, "Research on calculation of new energy's power generation efficiency and analysis on its driving factors," Resources Science, vol. 38, pp. 1-12, 2016.

[52] L. Y. Cai, J. F. Guo, and Q. Ji, "Evaluation of new and renewable energy power generation performance in G8 and BRIC Nations," Resources Science, vol. 35, pp. 250-260, 2013.

[53] M. Shi, D. Zhang, P. Zou, and D. Broadstock, "Efficiency in the renewable energy sector in China," The Journal of Quantitative \& Technical Economics, vol. 33, pp. 60-77, 2016. 
[54] X. Zhang and X. Bai, "Incentive policies from 2006 to 2016 and new energy vehicle adoption in 2010-2020 in China," Renewable and Sustainable Energy Reviews, vol. 70, pp. 24-43, 2017.

[55] X. L. Xu and H. H. Chen, "Exploring the innovation efficiency of new energy vehicle enterprises in China," Clean Technologies and Environmental Policy, vol. 22, no. 8, pp. 1671-1685, 2020.

[56] D. M. Ceballos and Z. Dong, "The formal electronic recycling industry: challenges and opportunities in occupational and environmental health research," Environment International, vol. 95, pp. 157-166, 2016.

[57] K. Li, L. Fang, and L. He, "How urbanization affects China's energy efficiency: a spatial econometric analysis," Journal of Cleaner Production, vol. 200, pp. 1130-1141, 2018.

[58] P. Sheng, Y. He, and X. Guo, "The impact of urbanization on energy consumption and efficiency," Energy \& Environment, vol. 28, no. 7, pp. 673-686, 2017.

[59] S. T Katircioğlu, "Estimating higher education induced energy consumption: the case of Northern Cyprus," Energy, vol. 66, pp. 831-838, 2014.

[60] K. Si, X. L. Xu, and H. H. Chen, "Examining the interactive endogeneity relationship between R\&D investment and financially sustainable performance: comparison from different types of energy enterprises," Energies, vol. 13, pp. 1-15, 2020.

[61] B. Q. Lin and R. R. Luan, "Are government subsidies effective in improving innovation efficiency? Based on the research of China's wind power industry," The Science of the Total Environment, vol. 710, Article ID 136339, 2020.

[62] H. Liu, M. Lei, H. Deng, G. Keong Leong, and T. Huang, "A dual channel, quality-based price competition model for the WEEE recycling market with government subsidy," Omega, vol. 59, pp. 290-302, 2016.

[63] Z. Lu and S. Shao, "Impacts of government subsidies on pricing and performance level choice in Energy Performance Contracting: a two-step optimal decision model," Applied Energy, vol. 184, pp. 1176-1183, 2016.

[64] S. Jenniches and ", "Assessing the regional economic impacts of renewable energy sources - a literature review," Renewable and Sustainable Energy Reviews, vol. 93, pp. 35-51, 2018.

[65] J. Viholainen, M. Luoranen, S. Väisänen, A. Niskanen, M. Horttanainen, and R. Soukka, "Regional level approach for increasing energy efficiency," Applied Energy, vol. 163, pp. 295-303, 2016.

[66] S. Jenniches and E. Worrell, "Regional economic and environmental impacts of renewable energy developments: solar PV in the Aachen Region," Energy for Sustainable Development, vol. 48, pp. 11-24, 2019.

[67] L. J. Fan, N. Li, and Y. E. Chen, "Study on regional differences in technical efficiency of Chinese high-tech industries," Systems Engineering, vol. 29, pp. 56-62, 2011.

[68] B. Lin and X. Wang, "Exploring energy efficiency in China's iron and steel industry: a stochastic frontier approach," Energy Policy, vol. 72, pp. 87-96, 2014.

[69] J. Xu and J. Li, "The impact of intellectual capital on SMEs' performance in China," Journal of Intellectual Capital, vol. 20, no. 4, pp. 488-509, 2019.

[70] J. Xu, Y. Shang, W. Yu, and F. Liu, "Intellectual capital, technological innovation and firm performance: evidence from China's manufacturing sector," Sustainability, vol. 11, pp. pp1-15, 2019.

[71] X.-L. Xu, X. N. Yang, L. Zhan, C. K. Liu, N.-DE. Zhou, and $\mathrm{M}$. $\mathrm{Hu}$, "Examining the relationship between intellectual capital and performance of listed environmental protection companies," Environmental Progress \& Sustainable Energy, vol. 36, no. 4, pp. 1056-1066, 2017.

[72] X. L. Xu and Y. J. Chen, "A comprehensive model to analyze straw recycling logistics costs for sustainable development: evidence from biomass power generation," Environmental Progress \& Sustainable Energy, vol. 39, pp. 1-11, 2020.

[73] P. Sadorsky, "Do urbanization and industrialization affect energy intensity in developing countries?" Energy Economics, vol. 37, pp. 52-59, 2013.

[74] Q. Wang, "Effects of urbanisation on energy consumption in China," Energy Policy, vol. 65, pp. 332-339, 2014.

[75] X. L. Xu, S. Qiao, and H. H. Chen, "Exploring the efficiency of new energy generation: evidence from OECD and non-OECD countries," Energy \& Environment, vol. 31, no. 3, pp. 389-404, 2020.

[76] X.-L. Xu and H. H. Chen, "Exploring the relationships between environmental management and financial sustainability in the energy industry: linear and nonlinear effects," Energy \& Environment, vol. 31, no. 7, pp. 1281-1300, 2020.

[77] I. GA. The, "Database of international geothermal association," 2021, https://www.geothermal-energy.org/explore/ourdatabases/.

[78] E. PS. EPS, “Global statistical platform," 2021, https://www. epsnet.com.cn/.

[79] "IRENA data and statistics of international renewable energy agency," 2021, https://www.irena.org/Statistics.

[80] Devex.Bloomberg, "New energy finance (BNEF)," 2021, https://www.devex.com/organizations/bloomberg-newenergy-finance-bnef-50984.

[81] M. J. Farrell, "The measurement of productive efficiency," Journal of the Royal Statistical Society: Series A, vol. 120, no. 3, pp. 253-281, 1957.

[82] M. J. Farrell and M. Fieldhouse, "Estimating efficient production functions under increasing returns to scale," Journal of the Royal Statistical Society: Series A, vol. 125, no. 2, pp. 252-267, 1962.

[83] S. C. Kumbhakar and C. A. K. Lovell, Stochastic Frontier Analysis, Cambridge University Press, Cambridge, UK, 2003.

[84] G. E. Battese and T. J. Coelli, "A model for technical inefficiency effects in a stochastic frontier production function for panel data," Empirical Economics, vol. 20, no. 2, pp. 325-332, 1995.

[85] P. Ghoshal and B. Goswami, "Cobb-douglas production function for measuring efficiency in indian agriculture: a region-wise analysis," Economic Affairs, vol. 62, no. 4, pp. 573-579, 2017.

[86] W. Li, " $1 \%$ of increase in urbanization rate needs 60 Mtce," 2014.

[87] J. Zhang, R. Leng, M. Chen, X. Tian, and N. Zhang, "The future role of nuclear power in the coal dominated power system: the case of Shandong," Journal of Cleaner Production, vol. 256, Article ID 120744, 2020.

[88] J. Liu and W. Wei, "Impact of urbanization level and endowment disparity on carbon reduction efficiency," China Population, Resources and Environment, vol. 24, pp. 42-48, 2014. 